\title{
Epífitos vasculares do Refúgio de Vida Silvestre Banhado dos Pachecos
}

Josy Z. Matos

Rosana Farias-Singer

Fundação Zoobotânica do Rio Grande do Sul (FZB/RS), Porto Alegre, RS, Brasil.

Rosana Senna

E-mails: josy-matos@fzb.rs.gov.br

Ricardo Aranha Ramos rosana-singer@fzb.rs.gov.br rosana-senna@fzb.rs.gov.br ricardo-ramos@fzb.rs.gov.br

Andréia Maranhão Carneiro andreia-carneiro@fzb.rs.gov.br

Recebido em: 20 mar. 2017. Revisado em: 21 mar. 2017. Aceito: 02 abr. 2017. DOI: http://dx.doi.org/10.21674/2448-0479.34.798-806

\section{Resumo}

Este trabalho visa conhecer a riqueza de epífitos vasculares do Refúgio de Vida Silvestre Banhado dos Pachecos. Utilizando o método de Caminhamento adaptado foram inventariadas duas áreas com formações distintas: mata paludosa e mata de restinga. As plantas observadas foram fotografadas e identificadas. No total foram encontradas 35 espécies pertencentes a 20 gêneros e seis famílias. A família Orchidaceae foi a mais diversa, com 13 espécies, seguida por Bromeliaceae, com nove espécies, Cactaceae e Polypodiaceae com quatro, Piperaceae com três e Dryopteridaceae com duas. A 
mata de restinga apresentou maior número de espécies (26), enquanto que na mata paludosa foram encontradas 22 . O levantamento florístico apontou um considerável número de espécies epifíticas o que demonstra a importância ambiental do RVS Banhado dos Pachecos para a manutenção dos ecossistemas que contemplam a sinúsia epifítica.

Palavras-chave: Epífitos Vasculares. Restinga. Paludosa.

\section{Introdução}

O hábito epífitico é encontrado em vários grupos de plantas vasculares, como pteridófitas, gimnospermas e angiospermas. De acordo com Benzing (1990), este modo de vida está presente em diferentes famílias, representando até 84 famílias (por exemplo, Orchidaceae, Bromeliaceae, Aspleniaceae, Moraceae, Piperaceae, entre outras), sendo que $80 \%$ das espécies pertencem ao grupo de monocotiledôneas (KRESS, 1989).

Os epífitos estão presentes em praticamente todo o mundo, especialmente nas florestas tropicais úmidas, onde se encontram em maior diversidade (BENZING, 1990). Ocupam ambientes dos mais diversos, desde muito secos até as florestas úmidas. A família Orchidaceae é a que tem maior êxito em colonizar árvores, sendo que aproximadamente dois em cada três epífitos são orquídeas e $70 \%$ das espécies desta família são epífitos. Na família Bromeliaceae aproximadamente a metade das espécies é epífita. Entre as pteridófitas cerca de $30 \%$ das espécies, $39 \%$ dos gêneros e $34 \%$ das famílias são tipicamente epifíticas (KERSTEN, 2010). 
Nesta situação, a distribuição dentro das florestas mostra um intrincado padrão, havendo um alto grau de especialização entre plantas epífitas (KRÖMER et al., 2007). Sua presença em forófitos (plantas que suportam as epífitas) depende das exigências ecológicas de cada espécie. No interior da floresta, a luz e a umidade mostram um gradiente a partir do dossel, que é ocupado por diferentes epífitos, dependendo de suas necessidades ecológicas (NEIDER et al., 2001).

O fato das florestas tropicais estarem em grande risco de desaparecimento faz com que haja maior necessidade de criação e manutenção de áreas protegidas. Ainda se sabe muito pouco acerca do gerenciamento da biodiversidade nessas áreas (LAURENCE et al., 2012). Estudos que visem o conhecimento da riqueza das espécies e dos ecossistemas inseridos em unidades de conservação são de grande importância para fornecer subsídios para a tomada de decisões em gestão ambiental. Este trabalho visa conhecer a riqueza de epífitos vasculares do Refúgio de Vida Silvestre Banhado dos Pachecos.

\section{Materiais e Métodos}

O levantamento de epífitas foi realizado no Refúgio de Vida Silvestre Banhado dos Pachecos (DECRETO 41559 02/RS), situado ao oeste da planície costeira do Rio Grande do Sul, no município de Viamão, inserido no bioma Pampa. Esta Unidade de Conservação (UC) abrange uma área de 2.543,36 ha e está inserida na Área de Proteção Ambiental do Banhado Grande com formação de banhados, campos úmidos, mata paludosa e mata de restinga. O Refúgio 
é uma importante área de preservação no Estado por ser o reduto do cervo-do-pantanal (Blastocerus dichotomus) no Rio Grande do Sul, além de constituir abrigo para a fauna local e migratória (http://www.sema.rs.gov.br/refugio-de-vida-silvestre-banhado-dospachecos). $O$ trabalho foi realizado em áreas com formações distintas e com ocorrência de epífitas: mata de restinga e mata paludosa. Através do método de Caminhamento (FILGUEIRAS et al., 1994) adaptado, as áreas foram percorridas e todos os epífitos encontrados foram registrados, fotografados e identificados.

\section{Resultados e Discussão}

Foram encontradas 35 espécies de epífitas na área do RVS Banhado dos Pachecos, pertencentes a 20 gêneros (tabela 01). A família Orchidaceae foi a mais diversa, com 13 espécies, seguida por Bromeliaceae, com nove espécies, Cactaceae e Polypodiaceae com quatro e Piperaceae com três e Dryopteridaceae com duas. A maior riqueza de espécies foi encontrada na área de mata de restinga, com 26 espécies, enquanto a mata paludosa apresentou 22.

A família Orchidaceae geralmente é a mais numerosa em estudo de epífitas (HIETZ; HIETZ-SEIFER, 1995; KERSTEN; Silva, 2001, 2002; BORGO et al., 2002), seguida por Bromeliaceae, como demonstrado por este estudo. Os gêneros mais diversos foram Tillandsia, com quatro espécies, seguido por Gomesa e Peperomia, ambos com três espécies. Cabe destacar a presença de $T$. usneoides que ocupa as bordas das matas de restinga e paludosa em abundância. Esta espécie é considerada 


\section{um extremo de adaptação epifítica utilizando o forófito apenas como função mecânica para suporte (BENZING, 2000).}

Tabela 01. Epífitos do Refúgio da Vida Silvestre Banhado dos Pachecos (Viamão, Rio Grande do Sul) de acordo com a vegetação (Res - Restinga e Pal -

Paludosa).

\begin{tabular}{|c|c|c|c|}
\hline \multirow{2}{*}{ Família } & \multirow{2}{*}{ Espécie } & \multicolumn{2}{|c|}{ Vegetação } \\
\hline & & Res & Pal \\
\hline \multirow{9}{*}{ Bromeliaceae } & Aechmea recurvata (Klotzsch) L.B. Smith. & 1 & 1 \\
\hline & Billbergia alfonsi-joannis Reitz & & 1 \\
\hline & Tillandsia aeranthos (Loisel.) L.B.Smith & 1 & \\
\hline & T.geminiflora Brongn. & 1 & 1 \\
\hline & T.stricta Sol. ex Ker Gawl. & & 1 \\
\hline & T. tenuifolia L. & 1 & \\
\hline & T. usneoides (L.) L. & & 1 \\
\hline & Vriesea friburguensis Mez. & 1 & 1 \\
\hline & V. gigantea Gaudich. & 1 & 1 \\
\hline \multirow{4}{*}{ Cactaceae } & Lepismium cruciforme (Vell.) Kuntze & 1 & 1 \\
\hline & L. Iumbricoides (Lem.) Barthlott & & 1 \\
\hline & Rhipsalis teres (Vell.) Steud. & 1 & 1 \\
\hline & R. florcosa Salm-Dyck ex Pfeiff & & 1 \\
\hline \multirow[t]{2}{*}{ Dryopteridaceae } & Polybotrya cylindrica Kaulf. & & 1 \\
\hline & Rumohra adiantiformis (G.Forst.) Ching & 1 & 1 \\
\hline \multirow{13}{*}{ Orchidaceae } & Acianthera sp.1 & & 1 \\
\hline & A.glumacea (Lindl.) Pridgeon \& M.W.Chase & & 1 \\
\hline & Anathallis adenochila (Loefgr.) F.Barros & 1 & 1 \\
\hline & Cattleya intermedia Graham ex Hook. & & 1 \\
\hline & C. tigrina A.Rich. & 1 & \\
\hline & Campylocentrum aromaticum Barb.Rodr. & 1 & 1 \\
\hline & C. pauloense Hoehne \& Schltr. & 1 & 1 \\
\hline & Eurystyles cotyledon Wawra & 1 & \\
\hline & Gomesa barbata (Lindl.) M.W.Chase \& N.H.Williams & 1 & 1 \\
\hline & G. bifolia (Sims) M.W.Chase \& N.H.Williams & 1 & \\
\hline & G. flexuosa (G.Lodd.) M.W.Chase \& N.H.Williams & 1 & \\
\hline & Octomeria juncifolia Barb.Rodr. & 1 & \\
\hline & Trichocentrum pumilum (Lindl.) M.W.Chase \& N.H.Williams & 1 & 1 \\
\hline \multirow{3}{*}{ Piperaceae } & Peperomia catharinae Miq. & 1 & \\
\hline & P. glabella (Sw.) A.Dietr. & 1 & \\
\hline & P. pereskiaefolia (Jacq.) Kunth & 1 & \\
\hline \multirow{4}{*}{ Polypodiaceae } & Microgramma squamulosa (Kaulf.) de la Sota & 1 & 1 \\
\hline & M. vacciniifolia (Langsd. \& Fisch.) Copel. & 1 & \\
\hline & Niphidium crassifolium (L.) Lellinger & 1 & \\
\hline & Pleopeltis pleopeltifolia (Raddi) Alston & 1 & \\
\hline
\end{tabular}


Algumas espécies de pteridófitas são extremamente adaptadas ao ambiente epifítico. Com caules (rizomas) estreitos e suculentos, longamente pendentes e ramificados, coberto de escamas Micrograma squamulosa e M.vacciinifolia ocupam espaços aéreos não utilizados por outras espécies, seus caules também resistem a longos períodos de seca. Pleopeltis pleopeltifolia tem adaptações para falta de água, as frondes são poiquiloídricas, a planta ressecada "ressuscita" com aumento de umidade atmosférica.

Embora algumas espécies como Billbergia alfonsi-joannis e Eurystyles cotyledon tenham sido raras neste estudo, estando representadas por apenas um indivíduo a maioria das espécies encontradas são comuns na área. No entanto, cabe salientar o papel importante das espécies comuns na manutenção dos ecossistemas. Bromélias como Vriesea gigantea possuem a capacidade de manter um microssistema aquático chamado fitotelmata (fito=planta, telma= pântano) que envolve um extraordinário sistema de associação com outras espécies. Esta espécie pode conter até 2,5 litros de água de chuva acumulados (VELOSO, 1952). Nesta água, também se acumula matéria orgânica a partir de árvores do dossel que, uma vez decomposta por microorganismos é consumida pelos animais. Os nutrientes resultantes são absorvidos pelos tricomas especializados na base de folhas (BENZING, 1990). Assim, este grupo de plantas possui uma forte interação com a fauna, formada por mamíferos, anuros, diversos grupos de insetos, inclusive formigas, e vertebrados, especialmente as aves (BENZING, 2000). No bioma Mata Atlântica essa relação já está bem demonstrada por Cestari (2009) que encontrou 87 espécies de aves que visitam 85 espécies de bromélias. Nesse mesmo bioma, no sudeste brasileiro, 
as bromélias representam $30 \%$ das plantas utilizadas por beijaflores e $36 \%$ das plantas utilizadas pelos morcegos (SAZIMA et al., 1996, SAZIMA et al., 1999). Existe uma relação entre a diversidade de bromélias e o número de espécies de polinizadores associada à oferta de recursos pelas bromélias, existindo partição do recurso com os beija-flores polinizadores (VARASSIN; SAZIMA, 2000). Estas plantas podem ser consideradas espécies chave para o estudo e a manutenção dos ecossistemas onde são encontradas (BENZING, 2000).

\section{Conclusão}

O levantamento florístico apontou um considerável número de espécies epifíticas o que demonstra a importância ambiental da RVS Banhado dos Pachecos para a manutenção dos ecossistemas que contemplam a sinúsia epifítica.

\section{Referências}

BENZING, D. H. Vascular epiphytes. General biology and related biota. Cambridge: Cambridge University Press, 1990. 376 p.

BENZING, D. H.. Bromeliaceae: profile of an adaptative radiation. Cambridge: Cambridge University Press, 2000. 690 p.

BORGO, M.; SILVA, S.M. \& PETEAN, M.P. Epífitos vasculares em um remanescente de floresta estacional semidecidual, município de Fênix, PR, Brasil. Acta Biologica Leopoldensia 24:121-130, 2002. 
CESTARI, C. Epiphyte plants use by birds in Brazil. Oecologia Brasiliensis 13, 689-712, 2009.

FILGUEIRAS, T. S.; BROCHADO, A. L.; NOGUEIRA, P.E.; GUALA II, G. F. Caminhamento - um método expedito para levantamentos florísticos qualitativos. Cadernos de Geociências v.2, n.4, p.39-43, 1994.

HIETZ-SEIFERT, U., HIETZ, P. \& GUEVARA, S. Epiphyte vegetation and diversity on remnant trees after forest clearance in southern Veracruz, Mexico. Biological Conservation, v. 75, n.2, 103-111, 1996.

KERSTEN, R.A. \& SILVA, S.M. Composição florística e estrutura do componente epifítico vascular em floresta da planície litorânea na Ilha do Mel, Paraná, Brasil. Revista Brasileira de Botânica, v. 24, 213-226, 2001.

KERSTEN, R.A. \& SILVA, S.M.. Florística e estrutura do componente epifítico vascular em Floresta Ombrófila Mista Aluvial do rio Barigüi, Paraná, Brasil. Revista Brasileira de Botânica, v. 5, 259-267, 2002.

KRÖMER, T. K., M. GRADSTEIN, S. Vertical stratification of vascular epiphytes in submontane and montane forest of the Bolivian Andes: the importance of the understory. Plant Ecology, v. 189, n.2, 261-278, 2007. 5

LAURANCE, W. F. et. al. Averting biodiversity collapse in tropical forest protected areas. Nature, v. 489, 290-294, 2012.

NIEDER, J., J. PROSPERÍ, et al. Epiphytes and their contribution to canopy diversity. Plant Ecology, v. 153, n.1, 51-63, 2001.

SAZIMA, I., BUZATO, S. \& SAZIMA, M. An assemblage of hummingbird-pollinated flowers in a montane forest in southeastern Brazil. Botanica Acta, v. 109, 149-160, 1996. 
SAZIMA, M., BUZATO, S. \& SAZIMA, I. Bat-pollinated Flower Assemblages and Bat Visitors at Two Atlantic Forest Sites in Brazil. Annals of Botany, v. 83, 705-712, 1999.

VARASSIN, I. G. \& SAZIMA, M. Recursos de Bromeliaceae utilizados por beija-flores na Mata Atlântica no sudeste do Brasil. Bol. Mus. Biol. Mello Leitão, v. 11, n.12, 57-70, 2000.

VELOSO, H. P. O Problema ecológico vegetação - BromeliáceasAnofelinos. Anais Botânicos, v. 4, 187-229, 1952. 